1 CrystEngComm, Royal Society of Chemistry, 2019, 21 (26),

2 pp.3974-3981. $\langle 10.1039 /$ C9CE00488B $\rangle$

\title{
3 Chemical vapor deposition of titanium nitride thin 4 films: kinetics and experiments
}

Juan Su ${ }^{1}$, Raphaël Boichot ${ }^{1,}$, Elisabeth Blanquet ${ }^{1}$, Frédéric Mercier ${ }^{1}$, and Michel Pons ${ }^{1}$

1 Univ. Grenoble Alpes, CNRS, Grenoble INP*, SIMaP, F-38000 Grenoble, France. * Institute of Engineering Univ. Grenoble Alpes; juan.su@grenoble-inp.fr; elisabeth.blanquet@grenoble-inp.fr; frederic.mercier@grenoble-inp.fr; michel.pons@grenoble-inp.fr

* Correspondence: raphael.boichot@grenoble-inp.fr; Tel.: +33-476826537

Received: date; Accepted: date; Published: date

Abstract: Titanium nitride (TiN) films were grown by CVD (Chemical Vapor Deposition) from titanium chlorides generated in situ by direct chlorination of titanium metal, ammonia $\left(\mathrm{NH}_{3}\right)$ and hydrogen $\left(\mathrm{H}_{2}\right)$ as carrier gas on single crystal c-plane sapphire $\left(\mathrm{Al}_{2} \mathrm{O}_{3}\right)$, cemented carbides (WC-Co), stainless steel (AFNOR Z150CDV12) and amorphous graphite substrates. Kinetic pathways involving four surface reactions has been proposed to simulate the growth rate. The proposed model has been validated by experiments performed at different temperatures $\left(650-1400{ }^{\circ} \mathrm{C}\right)$, pressures (300-1000 Pa), with different amount of precursors (N/Ti ratio in gas phase) and on different substrates. The study shows that on polycrystalline materials, the crystal orientation depends on supersaturation while (111) preferred orientation is forced by underlying c-plane sapphire whatever the supersaturation. The low $\mathrm{N} / \mathrm{Ti}$ ratio in gas phase leads to low growth rate and dense TiN film which is the key to obtain golden TiN. The high growth rate corresponds to brown TiN. Globally, the study shows that golden color is independent from texture and is just the natural aspect of a dense stoichiometric TiN layer.

Keywords: TiN; Chemical Vapor Deposition; Supersaturation; Decorative and functional coatings.

\section{Introduction}

Thin films of titanium nitride (TiN) have been widely applied as wear resistant coatings for tools [1-6], diffusion barrier layers [7-10], decorative layers [11,12] and for its high hardness, thermal and chemical stability and good electrical conductivity. Chemical Vapor Deposition (CVD) [13] is a common technique for the growth of TiN thin films [5,6,12,14-16]. Particularly, two major chemical systems for the thermal CVD of TiN coatings, $\mathrm{TiCl}_{4}-\mathrm{N}_{2}-\mathrm{H}_{2}$ and $\mathrm{TiCl}_{4}-\mathrm{NH}_{3}-\mathrm{H}_{2}$, are used [17]. The temperature range for the first system is $900-1200{ }^{\circ} \mathrm{C}$ due to the low reactivity of nitrogen [18]. The temperature range for the second system can be easily lowered to $550-750{ }^{\circ} \mathrm{C}$ [12]. The effects of process parameters on the growth rate of CVD TiN coatings have been studied by Kuo et al. [19] for the $\mathrm{TiCl}_{4}-\mathrm{N}_{2}-\mathrm{H}_{2}$ system and by Jiang et al. [20] for the $\mathrm{TiCl}_{4}-\mathrm{NH}_{3}-\mathrm{H}_{2}$ system. Due to the complexity of the process parameters, their experiments were only focused on process parameters such as partial pressure, temperature and the N/Ti ratio in gas phase. To the date, it is still difficult to predict which process conditions will lead to a certain texture or visual aspect in TiN due to discrepancies in the effect of parameters according to different authors and scattered data. In general, the growth rate is positively affected by increasing $\mathrm{H}_{2}, \mathrm{~N}_{2}$, and $\mathrm{NH}_{3}$ partial pressures but a positive to negative dependence of growth rate to increasing $\mathrm{TiCl}_{4}$ partial pressure is observed in literature [17,21]. It results from the formation of a non-reactive complex, $\mathrm{TiCl}_{4} \mathrm{NH}_{3}$ in the gas phase. In this work, comprehensive link between supersaturation, temperature and growth rate will be presented combining experiments with CFD simulation. 
A global kinetic model of TiN growth from $\mathrm{TiCl}_{4}-\mathrm{N}_{2}-\mathrm{H}_{2}$ system was proposed in Ref. [17,21]. A detailed kinetic mechanism and reaction pathways were built for the $\mathrm{TiCl}_{4}-\mathrm{NH}_{3}-\mathrm{H}_{2}$ system by Larson et al. and Allendorf et al. [22,23], but only for a temperature of $630^{\circ} \mathrm{C}$. They estimated the growth rate by a series of surface reactions considering 4 gases, 10 surface sites and 2 bulk species. Grujicic et al. [24] applied this mechanism for multi-length scale modeling and showed that the grain size increased with increasing coating thickness. The thermodynamics and kinetics of gas-phase reactions in the Ti$\mathrm{Cl}-\mathrm{H}$ system was studied by Teyssandier et al. [25], the rate coefficients of decomposition of $\mathrm{TiCl}_{4}$ and $\mathrm{TiCl}_{3}$ [25] were confirmed by experiments at high temperature $\left(1000-1200{ }^{\circ} \mathrm{C}\right)$ in Ref. [26]. The aim of this study is: (1) to assess simplified reaction pathways for the simulation of $\mathrm{TiN}$ growth with $\mathrm{TiCl}_{\mathrm{x}}$ $\mathrm{NH}_{3}-\mathrm{H}_{2}$ system based on the study of Larson and Allendorf [22] and extend it to a broad range of process temperature; (2) to improve the understanding of the relationships between growth rate, temperature, supersaturation, preferred orientation and morphology on ideal single crystal (c-plane sapphire) and polycrystalline materials (WC-Co, Stainless steel Z150CDV12, and amorphous graphite); (3) to figure out the main process parameters and the key feature for obtaining golden TiN.

\section{Experimental details}

TiN is grown on single crystal (0001) sapphire (The Roditi International corporation Ltd., London, UK), stainless steel (AFNOR Z150CDV12: 1.5\%C, 12\%Cr, 1\%Mo and 1\%V), WC-Co with 6 wt.\% Cobalt (Hyperion, Grenoble, France) and amorphous graphite (Graphitech company, Saint Martin d'Hères, France). Due to the high hardness, WC-Co is first polished with diamond discs and finished by diamond suspension $(1 \mu \mathrm{m})$. Stainless steel and graphite are finished with $1-\mu \mathrm{m}(2400$ grit) silicon carbide paper. These substrates are at the center of the graphite susceptor of $55 \mathrm{~mm}$ diameter. Deposition temperature is measured by a thermocouple $\left(20-700{ }^{\circ} \mathrm{C}\right)$ or an infrared pyrometer $\left(700-1400^{\circ} \mathrm{C}\right)$. The cold-wall experimental system used is shown in Figure 1. Ammonia $\mathrm{NH}_{3}(99.999 \%)$ gas is injected from the side of the quartz tube to minimize gas-phase reactions before deposition. The others gases are injected from the top of reactor. Chlorine gas $\mathrm{Cl}_{2}(99.999 \%)$ is injected into a chlorination tube which contains high purity titanium pellets (Goodfellow company, Coraopolis, PA, USA, purity of $99.98 \%$ ). Lamps at the top of the quartz tube allow the chlorination reactions. Induction coils $(20 \mathrm{kHz})$ are used to heat the graphite holder. The temperature of cooling water for the quartz tube is fixed at $85^{\circ} \mathrm{C}$ to minimize species condensation on walls. All the samples except graphite are cleaned by acetone, ethanol and isopropanol successively in an ultrasonic bath. Each cleaning procedure takes 5 minutes.

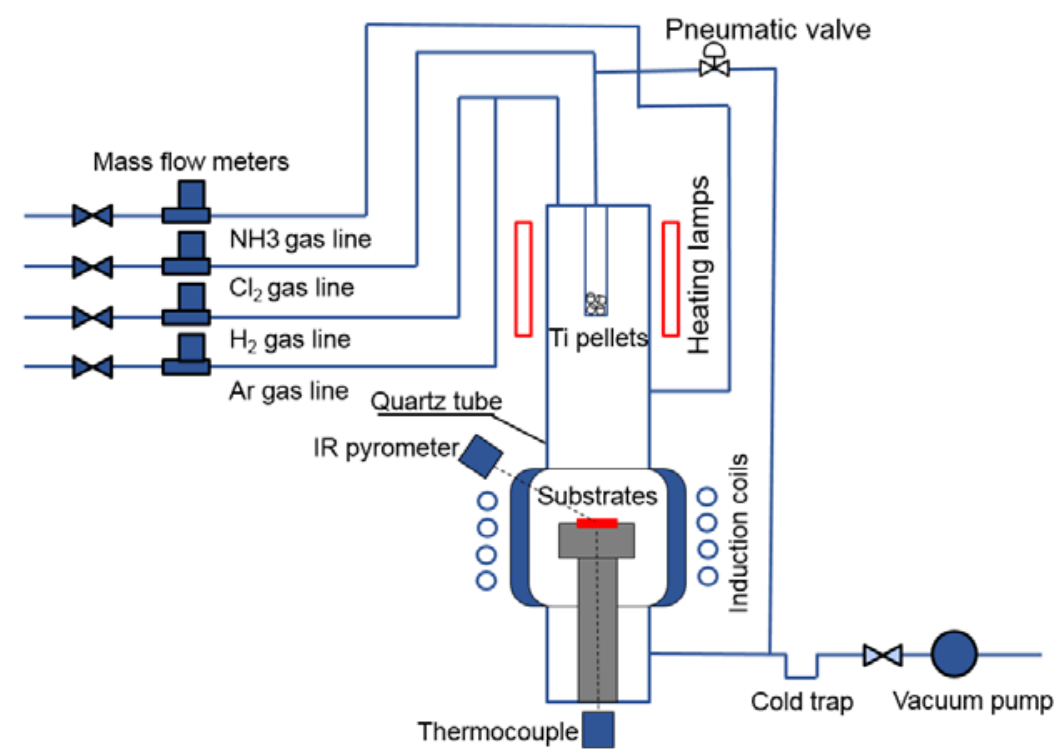

Figure 1. The cold wall experimental system for TiN CVD growth. 
At the beginning of each run, $200 \mathrm{sccm}$ of $\mathrm{H}_{2}$ are injected into the chlorination tube to clean the titanium pellets at $650{ }^{\circ} \mathrm{C}$ for 20 minutes (removing of carbon contamination on the surface). The substrates are then heated under $1000 \mathrm{sccm}$ of $\mathrm{H}_{2}$ with a $30 \mathrm{~K} / \mathrm{min}$ ramp to reach the working temperature, followed by a $10 \mathrm{~min}$ plateau (thermal stabilization). $\mathrm{NH}_{3}$ is injected into the reactor 1 min before chlorine to reduce the etching of substrates by chlorides, especially when substrates are WC-Co (cobalt is particularly sensitive to chlorine). At the end of the experiment, the chlorine gas is switch off 1 min before $\mathrm{NH}_{3}$. The $\mathrm{H}_{2}$ flow is then replaced by $1000 \mathrm{sccm}$ of $\mathrm{N}_{2}$. The substrates are cooled down with a $37 \mathrm{~K} / \mathrm{min}$ ramp.

In the present study, $\theta / 2 \theta$ scans are made with a PANalytical X'Pert Pro MPD two-circle diffractometer $(\theta-\theta, \mathrm{CuK} \alpha$, acceleration voltage of $45 \mathrm{kV}$ and current of $40 \mathrm{~mA}$ from a sealed $\mathrm{x}$-ray tube) equipped with a 1D linear detector. Field Emission Gun-Scanning Electron Microscope (ZEISS Ultra-55) is used to characterize TiN layers surface morphology and texture. Thermodynamic analysis of the gas-phase chemistry is made using Factsage 7.2 thermodynamic software and the thermodynamic database FactPS. For the modeling of TiN deposition, heat transfer, mass transport and gas flow dynamics are solved using the CFD-ACE+ multiphysics software package (2017 version).

Table 1 summarized the experiments performed for this study. Experimental as well as modeling results are summarized in this table and will be discussed in next sections. To obtain the surface activation energy, the last 5 experiments in Table 1 are designed to vary the deposition temperature while the N/Ti ratio and pressure in the reactor are fixed at 1.5 and $1000 \mathrm{~Pa}$, respectively. All the experiments in Table 1 are used to develop numerical modeling and simulation of TiN growth.

\section{Modeling and simulation}

\subsection{Thermodynamic equilibrum and gas-phase kinetic analysis}

For the traditional $\mathrm{TiN}$ coating system, $\mathrm{TiCl}_{4}$ is generated by dosing and vaporizing its liquid phase. This solution necessitates handling liquid $\mathrm{TiCl}_{4}$, a particularly corrosive product with a high vapor pressure. Teyssandier and Allendorf [25] have shown that $\mathrm{TiCl}_{4}$ is stable and remains the most important Ti-containing species when the temperature is below $900{ }^{\circ} \mathrm{C}$. In the chlorination system used here, $\mathrm{Cl}_{2}$ gas passes over Ti pellets, solid $\mathrm{TiCl}_{2}$ is theoretically the only chlorination product by thermodynamic calculation (large excess of titanium versus chlorine). This means that the titanium pellets are surrounded with solid $\mathrm{TiCl}_{2}$ during chlorination process, that reacts in a second time with $\mathrm{Cl}_{2}$. Figure 2 presents the thermodynamic equilibrium of $10 \mathrm{~mol} \mathrm{TiCl}_{2}(\mathrm{~s})$ and $2 \mathrm{~mol} \mathrm{Cl}_{2}(\mathrm{~g})$ at $1000 \mathrm{~Pa}$ in the $600-1000{ }^{\circ} \mathrm{C}$ temperature range, conditions close to our chlorination process. Some experiments are also carried out at around $300 \mathrm{~Pa}$ in this study, but the thermodynamic calculation shows that the total pressure does not affect the mole fraction of gaseous species. At $650{ }^{\circ} \mathrm{C}$ (chlorination temperature in the present work), the main gaseous species are $\mathrm{TiCl}_{3}(\mathrm{~g})$ and $\mathrm{TiCl}_{4}(\mathrm{~g})$ in equilibrium with solid-phase $\mathrm{TiCl}_{2}(\mathrm{~s})$. Additionally, the deposition of a purple powdered films on the quartz tube is an indication of the presence of $\mathrm{TiCl}_{3}(\mathrm{~g})$ (see Figure $\mathrm{S} 1$ in supplementary material). The mole fraction ratio is around $\mathrm{X}_{\mathrm{TiC} 13}: \mathrm{X}_{\mathrm{TiC} 14=8}: 2$.

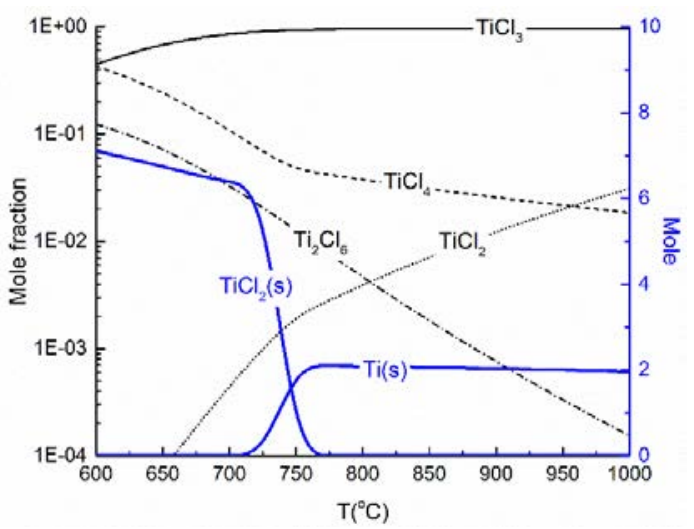


Table 1. Summary of the growth parameters. To calculate texture coefficient $\mathrm{T}_{\mathrm{c}}, 4$ main diffraction peaks are taken into account: (111), (200), (220) and (420).

\begin{tabular}{|c|c|c|c|c|c|c|c|c|c|c|}
\hline $\begin{array}{c}\text { Temperature } \\
{ }^{\circ} \mathrm{C}\end{array}$ & $\begin{array}{l}\text { Pressure } \\
\text { (Pa) }\end{array}$ & $\begin{array}{l}\mathrm{Sccm} \\
\mathrm{NH}_{3}\end{array}$ & $\begin{array}{c}\mathrm{Sccm} \\
\mathrm{Cl}_{2}\end{array}$ & $\begin{array}{l}\text { N/Ti in } \\
\text { gas } \\
\text { phase }\end{array}$ & $\begin{array}{c}\text { Measured } \\
\text { growth rate } \\
\left(\mu \mathrm{m} \cdot h^{-1}\right)\end{array}$ & $\begin{array}{c}\text { Theoretical } \\
\text { growth rate } \\
\left(\mu \mathrm{m} \cdot \mathrm{h}^{-1}\right)\end{array}$ & $\begin{array}{c}\log _{10} \text { (surface } \\
\text { supersaturation) }\end{array}$ & $\begin{array}{l}\text { Main texture } \\
\left(\mathrm{T}_{\mathrm{c}} \%\right) \text { on } \mathrm{c}- \\
\text { plane } \\
\text { sapphire }\end{array}$ & $\begin{array}{c}\text { Main texture }\left(\mathrm{T}_{\mathrm{c}} \%\right) \\
\left.\text { on } \mathrm{WC}-\mathrm{Co}^{*}\right), \\
\text { graphite }(\#), \operatorname{steel}(\&)\end{array}$ & $\begin{array}{c}\text { Color } \\
\text { on sapphire }\left(^{*}\right) \text { and } \\
\text { non-orientated } \\
\text { substrates }(\#)\end{array}$ \\
\hline 663 & 1000 & 25 & 20 & 1.875 & 1 & 2.9 & 13.4 & $111(94 \%)$ & $200 *(100 \%)$ & brown ${ }^{* \#}$ \\
\hline 663 & 1000 & 50 & 20 & 3.75 & 7.7 & 5.7 & 13.63 & $111(83 \%)$ & $200^{*}(100 \%)$ & brown ${ }^{* \#}$ \\
\hline 662 & 1000 & 50 & 10 & 7.5 & 5.7 & 5.64 & 13.57 & $111(91 \%)$ & $220^{*}(93 \%)$ & brown*\# \\
\hline 1100 & 1000 & 10 & 8 & 1.875 & 3 & 4.08 & 3.68 & $111(100 \%)$ & - & golden* \\
\hline 710 & 310 & 5 & 7.5 & 1.0 & 0.06 & 0.228 & 11.39 & $111(100 \%)$ & $200^{*}(100 \%)$ & silver ${ }^{*}$,golden \\
\hline 673 & 310 & 5 & 5 & 1.5 & 0.04 & 0.2 & 12.39 & $111(100 \%)$ & $200^{*}(100 \%)$ & silver*, golden \\
\hline 665 & 1000 & 50 & 20 & 3.75 & 8.4 & 5.8 & 13.57 & $111(73 \%)$ & $200^{*}(100 \%)$ & brown ${ }^{*}$ \\
\hline 604 & 1000 & 50 & 20 & 3.75 & 2.724 & 4.32 & 15.60 & $\begin{array}{l}111(57 \%), \\
200(34 \%)\end{array}$ & $200^{*}(100 \%)$ & brown ${ }^{* \#}$ \\
\hline
\end{tabular}


2 of 14

\begin{tabular}{|c|c|c|c|c|c|c|c|c|c|c|}
\hline $\begin{array}{c}\text { Temperature } \\
{ }^{\circ} \mathrm{C}\end{array}$ & $\begin{array}{l}\text { Pressure } \\
\text { (Pa) }\end{array}$ & $\begin{array}{l}\mathrm{Sccm} \\
\mathrm{NH}_{3}\end{array}$ & $\begin{array}{c}\mathrm{Sccm} \\
\mathrm{Cl}_{2}\end{array}$ & $\begin{array}{l}\mathrm{N} / \mathrm{Ti} \\
\text { in gas } \\
\text { phase }\end{array}$ & $\begin{array}{c}\text { Measured } \\
\text { growth rate } \\
\left(\mu \mathrm{m} \cdot \mathrm{h}^{-1}\right)\end{array}$ & $\begin{array}{c}\text { Theoretical } \\
\text { growth rate } \\
\left(\mu \mathrm{m} \cdot \mathrm{h}^{-1}\right)\end{array}$ & $\begin{array}{c}\log _{10} \text { (surface } \\
\text { supersaturation) }\end{array}$ & $\begin{array}{l}\text { Main texture } \\
\left(\mathrm{T}_{\mathrm{c}} \%\right) \text { on } \mathrm{c}- \\
\text { plane sapphire }\end{array}$ & $\begin{array}{c}\text { Main texture }\left(\mathrm{T}_{\mathrm{c}} \%\right) \\
\left.\text { on } \mathrm{WC}-\mathrm{Co}^{*}\right) \\
\text { graphite }(\#), \text { steel }(\&)\end{array}$ & $\begin{array}{c}\text { Color } \\
\text { on sapphire }\left(^{*}\right) \text { and } \\
\text { non-orientated } \\
\text { substrates( } \#)\end{array}$ \\
\hline 609 & 1000 & 50 & 20 & 3.75 & 3 & 4.32 & 15.42 & $111(86 \%)$ & $200 *(100 \%)$ & brown ${ }^{* \#}$ \\
\hline 619 & 1000 & 50 & 20 & 3.75 & 2.904 & 4.32 & 15.06 & $111(93 \%)$ & $200^{*}(100 \%)$ & brown $n^{* \#}$ \\
\hline 662 & 1000 & 30 & 10 & 4.5 & 6.5 & 3.48 & 13.39 & $111(100 \%)$ & $200 *(100 \%)$ & brown ${ }^{* \#}$ \\
\hline 662 & 1000 & 50 & 20 & 3.75 & 3.45 & 5.8 & 13.66 & $111(65 \%)$ & $200^{*}(100 \%)$ & brown*\# \\
\hline 650 & 1000 & 5 & 5 & 1.5 & 0.3 & 0.58 & 13.0 & - & $200^{\&}(100 \%)$ & golden ${ }^{\#}$ \\
\hline 680 & 1000 & 5 & 5 & 1.5 & 0.4 & 0.6 & 12.16 & - & $200^{\&}(100 \%)$ & golden ${ }^{\#}$ \\
\hline 750 & 1000 & 5 & 5 & 1.5 & 0.6 & 0.84 & 10.21 & - & $200^{\&}(69 \%)$ & brown $n^{\#}$ \\
\hline 800 & 1000 & 5 & 5 & 1.5 & 0.7 & 1.02 & 8.96 & - & $200^{\&}(69 \%)$ & brown ${ }^{\sharp}$ \\
\hline 1400 & 1000 & 5 & 5 & 1.5 & 3.8 & 3.1 & -0.135 & $111(100 \%)$ & $111^{\#}(62 \%)$ & Dark brown ${ }^{* \#}$ \\
\hline
\end{tabular}


For the traditional $\mathrm{TiCl}_{4}-\mathrm{NH}_{3}$ system, Umanskii et al. [27] studied the reaction pathways involving complex formation $\left(\mathrm{TiCl}_{x} \mathrm{NH}_{\mathrm{y}}\right)$. It was concluded that, in typical CVD conditions, only $\mathrm{TiCl}_{4} \mathrm{NH}_{3}$ is formed in substantial amount at low temperature. Grujicic et al. [24] took into account the presence of non-reactive complex formation. As $\mathrm{TiCl}_{4}(\mathrm{~g})$ concentration is increased, it causes additional $\mathrm{NH}_{3}(\mathrm{~g})$ to be tied up in the complex. This complex could be either poorly reactive, either with a very low vapor pressure and condensing. This decreases the concentration of $\mathrm{NH}_{3}(\mathrm{~g})$ available for the CVD of TiN and, in turn, decreases the deposition rate. The effect is a very small negative order of the TiN deposition rate with respect to the concentration of $\mathrm{TiCl}_{4}(\mathrm{~g})$. Teyssandier and Allendorf [25] developed a gas-phase kinetic model which corresponds to our experimental range. This dataset involving decomposition and formation of $\mathrm{TiCl}_{\mathrm{x}}(\mathrm{x}=1,2,3,4)$, and equilibrium reactions is used to understand gas-phase transformations as a function of temperature and pressure (see Table S2 in supplementary material).

\subsection{Mass transport modeling}

135

136

137

138

139

140

141

142

143

144

145

146

147

148

149

150

151

152

153

For mass transport modeling, the models and software packages already used for AIN deposition are used [28]. The governing equations of multicomponent mass transport and heat transfer can be found in Table S1 in supplementary material. The species properties such as diffusion coefficients, mixtures viscosities and thermal conductivities are calculated using the Enskog theory [29]. Lennard-Jones parameters for gaseous species are computed according to the empirical method in Ref. [30]. The laminar incompressible momentum equation is used to solve the diffusionconvection problem since the Reynolds number in all experiments is less than 50 . The mixture enthalpy is calculated by a polynomial relationship with temperature by JANAF formalism [31].

To simplify the surface reaction model and figure out which $\mathrm{TiCl}_{x}$ can be, $\mathrm{TiCl}_{x}$ mole fractions on the substrate as a function of temperature at $300 \mathrm{~Pa}$ and $1000 \mathrm{~Pa}$ considering the 17 gas-phase reactions of the Ti-Cl-H system (see Table S2 in supplementary material) has been calculated by CFDACE as shown in Figure 3. The typical inlet gas-phase mole fractions are $90 \% \mathrm{H}_{2}, 8 \% \mathrm{TiCl}_{3}$ and $2 \%$ $\mathrm{TiCl}_{4}$ since $\mathrm{X}_{\mathrm{TiCl}}$ : $\mathrm{X}_{\mathrm{TiCl} 4}=8: 2$ from thermodynamic equilibrium in chlorination tube. It can be seen that the mole fraction of $\mathrm{TiCl}_{2}$ is increasing and the mole fraction of $\mathrm{TiCl}_{4}$ is decreasing with temperature, regardless of pressure. This conclusion is in a good agreement with Ref. [25,32]. The mole fraction of $\mathrm{TiCl}_{3}$ is however almost stable, indicating that the decomposition and formation of $\mathrm{TiCl}_{3}$ are almost kinetically balanced. Figure 3 further illustrates that $\mathrm{TiCl}_{3}$ and $\mathrm{TiCl}_{4}$ only should be considered for surface reactions and $\mathrm{TiCl}_{2}$ can be ignored, because the mole fraction of $\mathrm{TiCl}_{2}$ is negligible in typical CVD conditions.

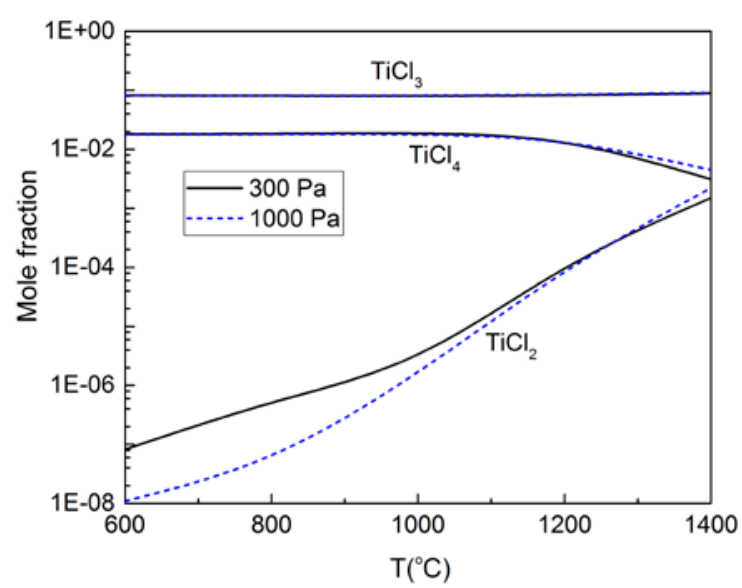

Figure 3. Mole fraction of $\mathrm{TiCl}_{x}$ at the substrate center as a function of the deposition temperature.

The kinetic model of surface reactions developed by Allendorf et al. [23] was first used to compare experimental and modeling results at $630^{\circ} \mathrm{C}$. This model involves 14 surface reactions and successfully predicts TiN growth rates as a function of key reactor parameters including inlet reactant concentrations, reactor pressures and total gas flow rates. This model will be modified to take into account the activation energy. 


\section{Results and discussion}

\subsection{Experimental growth rates versus modeling and the surface kinetic parameters}

Arrhenius plot obtained at fixed flow rate and pressure (last five experiments in Table.1) is shown in Figure 4. It shows that the growth rate is kinetically controlled with an activation energy of $43 \mathrm{~kJ} / \mathrm{mol}$.

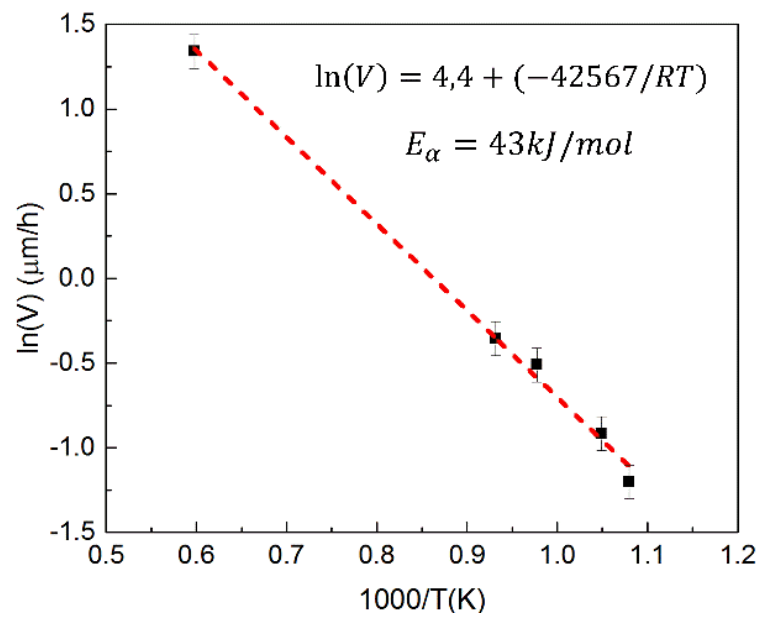

Figure 4. Arrhenius plots for TiN deposition.

From the previous kinetic database[23,25], a simplified kinetic model taking into account temperature variations is assumed.

$$
\begin{aligned}
\mathrm{TiCl}_{3}+\mathrm{NH}_{2-} s & \rightarrow \mathrm{N}(B)+\mathrm{TiCl}_{2-} s+\mathrm{HCl} \\
\mathrm{TiCl}_{4}+\mathrm{NH}_{2-} s & \rightarrow \mathrm{N}(\mathrm{B})+\mathrm{TiCl}_{3-} s+\mathrm{HCl} \\
\mathrm{NH}_{3}+\mathrm{TiCl}_{2-} s & \rightarrow \mathrm{Ti}(B)+\mathrm{NH}_{2-} s+\mathrm{HCl}+\mathrm{Cl} \\
\mathrm{NH}_{3}+\mathrm{TiCl}_{3-} s & \rightarrow \mathrm{Ti}(B)+\mathrm{NH}_{2-} s+\mathrm{HCl}+\mathrm{Cl}_{2}
\end{aligned}
$$

where three kinds of surface species on growing $\mathrm{TiN}$ surfaces are only considered: $\mathrm{TiCl}_{3} s, \mathrm{TiCl}_{2} s$ and $\mathrm{NH}_{2}$ s. Surface reaction rate and kinetic data can be found in supplementary materials (see Table S3 in supplementary material).

Surface kinetic parameters have been obtained by minimizing the relative difference between experimental and simulated growth rates while maintaining kinetics from the original database [23] and varying the activation energy. It should be noted that each surface reaction conserves the total number of surface species, i.e. surface sites. In the case of the first reaction, for example, when a gasspecies $\mathrm{TiCl}_{3}$ attaches to the surface, there is one bulk phase atom added to the solid and a new surface species created. Reactions (1)-(4) are bimolecular reactions.

Although there are some reports of $\mathrm{TiN}$ deposition rates in the literature for $\mathrm{TiCl}_{4}-\mathrm{NH}_{3}$ system $[21,23,33]$, the lack of detailed information makes it difficult to simulate the deposition rates published. The parity diagram between simulated and experimental growth rates from this work is presented in Figure 5. The experimental error originates from substrate temperature and thickness uncertainties. 


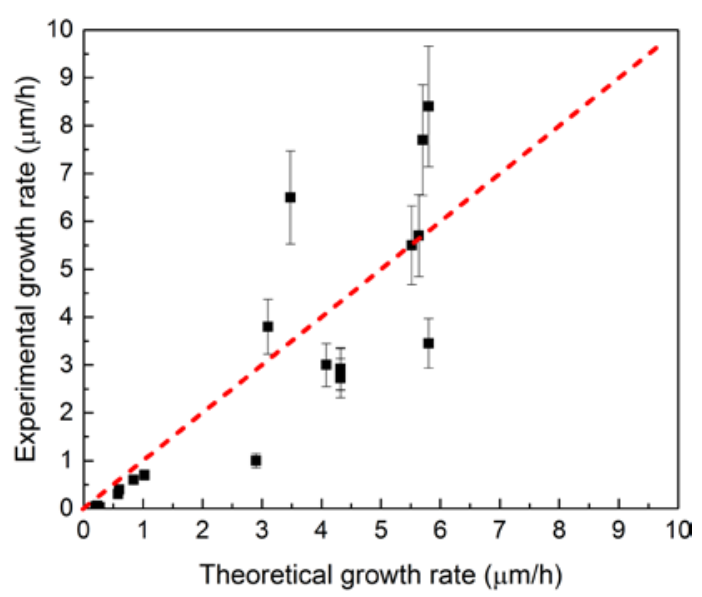

Figure 5. Parity diagram between experimental and theoretical growth rates from this work.

It is now possible to calculate the actual supersaturation (see equation S6 in supplementary materials for definition) just above the substrate by numerical modeling and to find relationships between processing parameters and microstructural information.

\subsection{Relationship among the texture of TiN, growth rate and supersaturation}

For each process conditions, the texture coefficient $\mathrm{T}_{\mathrm{c} \_ \text {hkl }}$ for each (hkl) plane of the obtained film is calculated as follows [34],

$$
T_{c_{-} h k l}=\frac{\frac{I_{h k l}}{I_{0, h k l}}}{\frac{1}{N} \cdot \sum_{1}^{N} \frac{I_{h k l}}{I_{0, h k l}}}
$$

in which $\mathrm{N}=4$ is the peak amount of TiN, $I_{h k l}$ and $I_{0, h k l}$ are the integrated intensity of the (hkl) Bragg reflection for the studied and for a randomly oriented samples, respectively, as give in ICDD: 00-0381420. In the present study, 4 main diffraction peaks (111), (200), (220) and (420) are taken into account. The percentage of texture coefficient $\mathrm{T}_{\mathrm{c}_{\_} \mathrm{hl}} \%$ is defined as $\mathrm{T}_{\mathrm{c}_{\_} \mathrm{kl}} / \mathrm{N}$ to show the preferred orientation of TiN films in the present work.

Figure 6 presents the relationship between the preferred orientation of TiN, growth rate, supersaturation, and deposition temperature on various substrates. In CVD, high deposition temperatures are generally correlated to low supersaturations. In Figure 6a, the substrates are stainless steel, WC-Co or graphite which are only poorly or randomly textured. It can be seen that the orientation of TiN is correlated with supersaturation. TiN film with (111) preferred orientation appears at low supersaturation (high temperature) while (200) and (220) preferred orientation are likely grown at high supersaturation (so low temperature), in agreement with Ref. [35]. In Figure 6b, the substrates are (0001) single crystal sapphire. Due to crystallographic relationships, the (0001) hexagonal lattice of sapphire imposes the (111) preferred orientation to the TiN film. High supersaturation ( $\log _{10}$ (supersaturation) $>15.5$ ) contributes to polycrystalline TiN film. It also can be seen from Figure 7 that there is no clear correlation between N/Ti ratio and the crystallographic orientation of TiN films. 


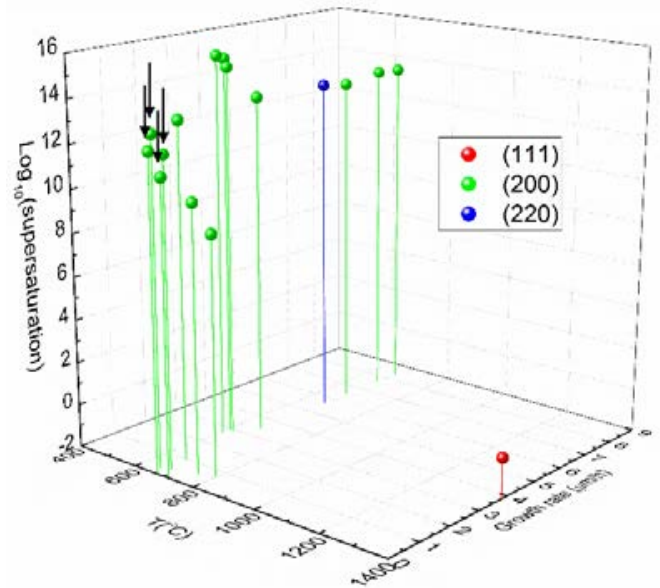

(a)

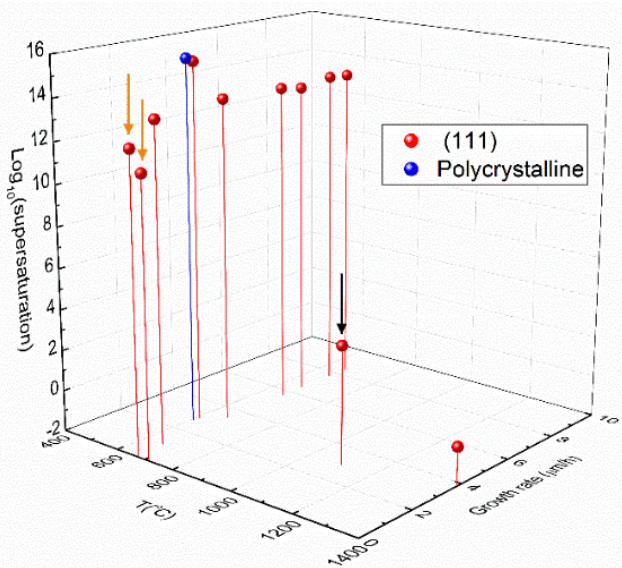

(b)

Figure 6. Relationships among preferred orientations, growth rates, supersaturation and deposition temperatures. (a) Substrates are WC-Co, stainless steel and graphite without preferred orientation. (b) Substrate is (0001) sapphire. Black arrows show TiN films with golden color and orange arrows show TiN films with silver color.

\subsection{The formation conditions and feature of golden TiN}

Even if the color of TiN film is affected by various properties such as composition, stoichiometry and thickness etc. [36], we studied color feature as function of process parameters (N/Ti gas phase ratio, supersaturation) and finally cross-section morphology. In Figure 6, the black and orange arrows point out the conditions for obtaining golden TiN films and silvery TiN films, respectively. On nonoriented substrates, golden color is obtained at rather low growth rate (less than $0.4 \mu \mathrm{m} / \mathrm{h}$ ). On $(0001)$ sapphire, silver and golden TiN films prefer low growth rate (less than $3 \mu \mathrm{m} / \mathrm{h}$ ). TiN films with both (200) and (111) preferred orientation can have golden color. Polycrystalline TiN with golden color can also be obtained (see Figure S2 in supplementary material). Therefore, the golden color of TiN is clearly not related with its texture.

In Ref. [37], the color of TiN films was studied in a small range of growth rates, less than $2 \mu \mathrm{m} / \mathrm{h}$. It showed that the color of TiN films was determined by N/Ti gas-phase ratio. In our experiments, the range of growth rate is from 0.03 to $8 \mu \mathrm{m} / \mathrm{h}$ at various $\mathrm{N} / \mathrm{Ti}$ ratios on single and polycrystalline substrates. So it is interesting to study TiN color according to these two parameters only. Figure 7 presents the influence of N/Ti on growth rate and color of TiN on non-orientated substrates (Figure 7a) and (0001) sapphire single crystal (Figure $7 \mathrm{~b}$ ). It can be seen that high N/Ti ratio leads to high growth rate. Figure 7a shows that on polycrystalline substrates, the color of TiN is mainly influenced by growth rate. The golden TiN can be obtained when the growth rate is below $0.4 \mu \mathrm{m} / \mathrm{h}$. Figure $7 \mathrm{~b}$ shows that the influence of N/Ti ratio and growth rate on the color of TiN films grown on (0001) sapphire single crystal is more complicated. The sapphire substrates have an ordered structure and transparent color. Golden color is difficult to obtain because TiN film with (111) crystallographic orientation prefers to grow as columnar layer, not dense enough. When the growth rate is less than $0.1 \mu \mathrm{m} / \mathrm{h}$, TiN films present a silvery color. The color of TiN films changes from silver to golden with deposition time (visual observation during experiments). When the N/Ti ratio is around 2 and growth rate is around $3 \mu \mathrm{m} / \mathrm{h}$, TiN film with shining golden color is obtained once. The brown TiN films are obtained when the growth rate is above $3 \mu \mathrm{m} / \mathrm{h}$ or N/Ti ratio is above 2. In conclusion, golden TiN films on non-orientated substrates are determined by a low growth rate $(\leq 0.4 \mu \mathrm{m} / \mathrm{h})$ while on sapphire film should be thick enough $(\approx 3 \mu \mathrm{m})$ and not columnar (dense). 


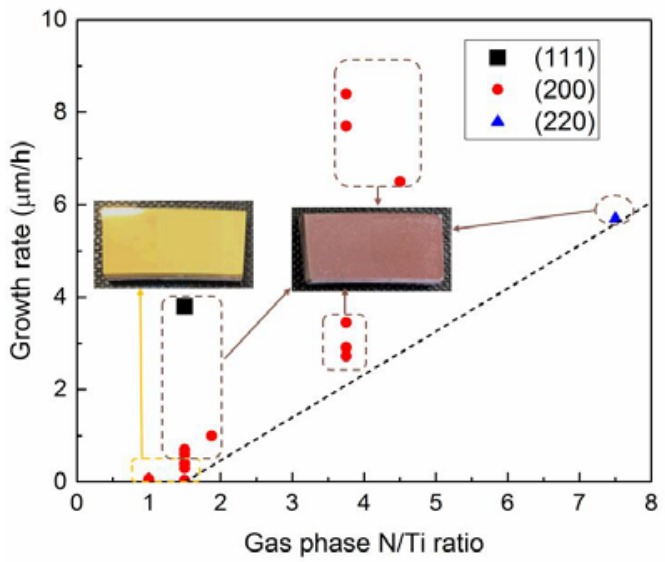

(a)

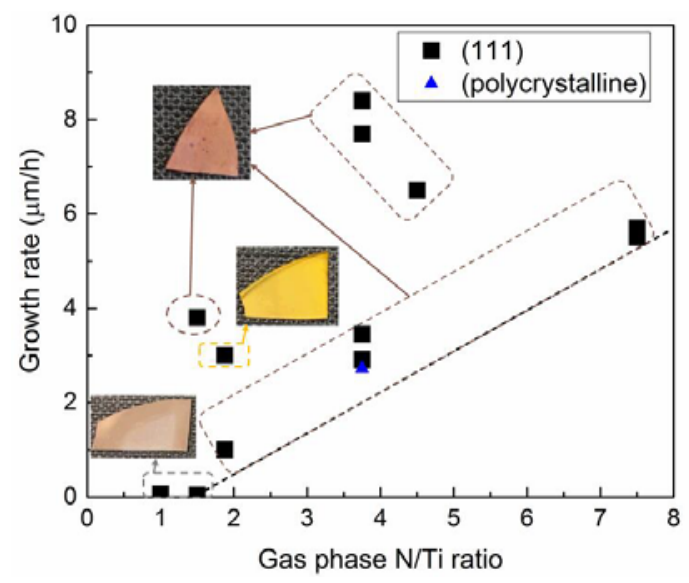

(b)

Figure 7. TiN growth rate versus N/Ti ratio on (a) non-orientated substrates and (b) (0001) sapphire. The figure also indicates the preferred orientation and color of TiN.

To show the structure difference between golden and brown TiN, Figure 8 shows cross-sectional morphology of (a) golden TiN on WC-Co, (b) brown TiN on WC-Co. On non-orientated substrates, it can be see that thin and dense TiN layers present golden color while TiN films with thick columnar structure present brown color.

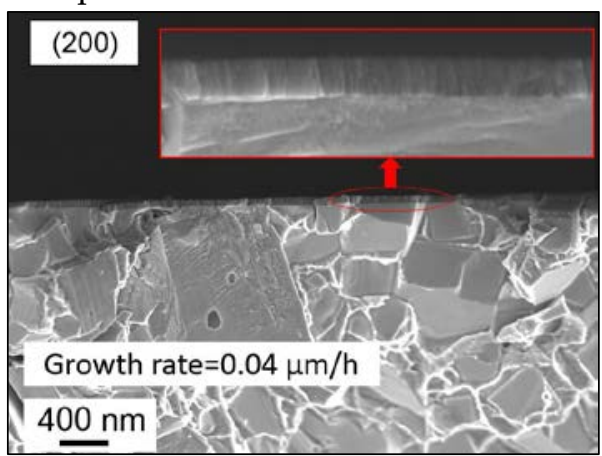

(a)

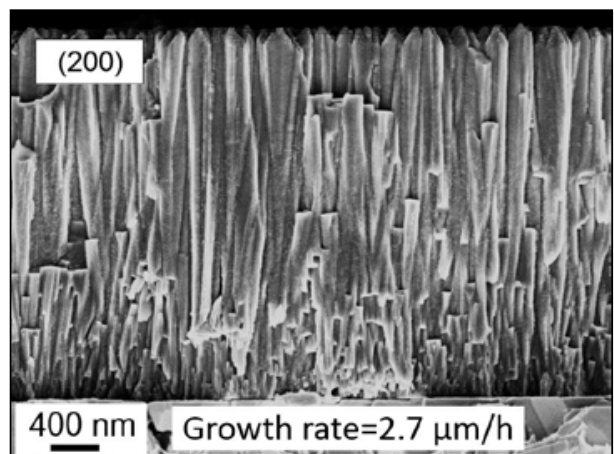

(c)

Figure 8. Cross-sectional morphology of (a) golden TiN on WC-Co (b) brown TiN on WC-Co. The figure also indicates preferred crystallographic direction and growth rate.

Three cross-sectional and surface morphology of TiN films: (a) golden, growth rate at $3 \mu \mathrm{m} / \mathrm{h}$, $\mathrm{N} / \mathrm{Ti}=1.875$, (b) brown, growth rate at $3 \mu \mathrm{m} / \mathrm{h}, \mathrm{N} / \mathrm{Ti}=3.75$ and (c) brown, growth rate at $5.7 \mu \mathrm{m} / \mathrm{h}$, $\mathrm{N} / \mathrm{Ti}=7.5$ on sapphire are shown in Figure 9. Morphology in Figure 9(a) shows very dense TiN film while there are gaps between columns in Figure 9(b) and (c). Especially (a) and (b) has the same growth rate and thickness, it indicates that dense structure is the key point for the golden TiN film. Increasing N/Ti ratio as shown in Figure 9(b) or increasing both N/Ti ratio and growth rate as shown in Figure 9(c) leads to columnar growth and present brown color. As a conclusion, dense TiN films are always golden. Low N/Ti ratio leads to high density.

(a)

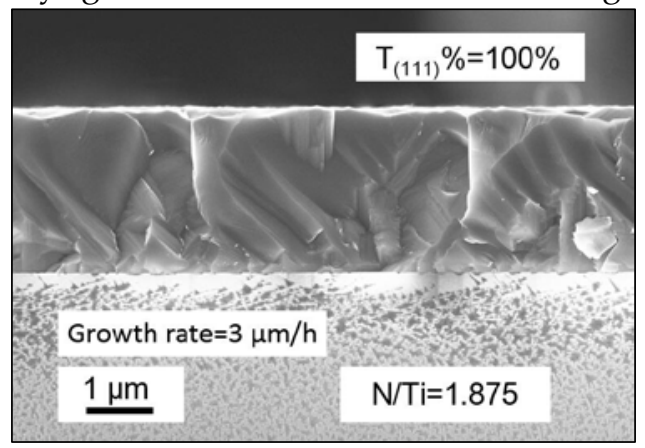

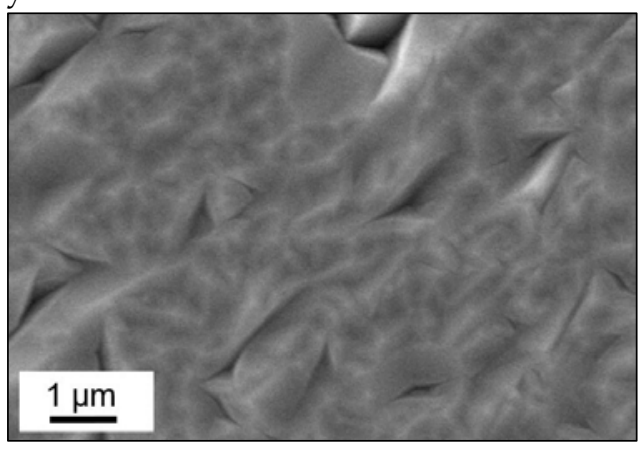


(b)

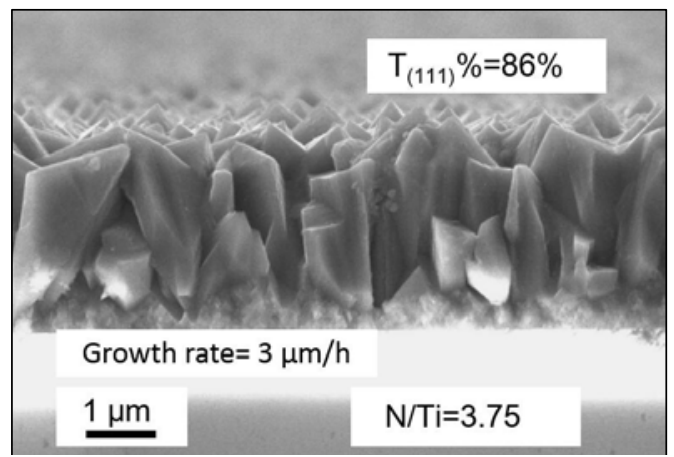

(c)

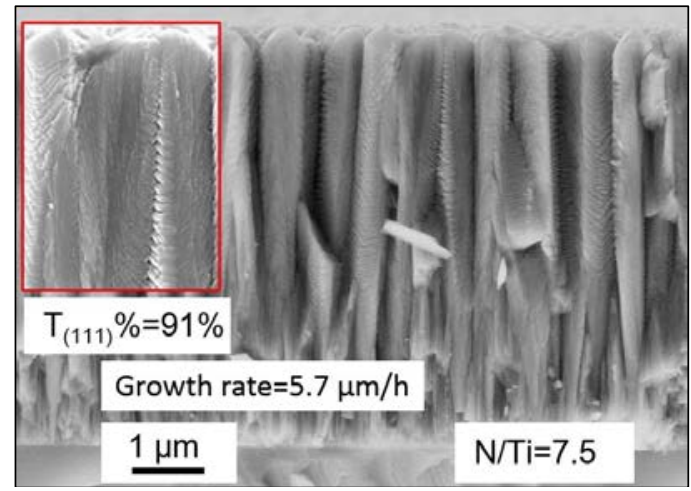

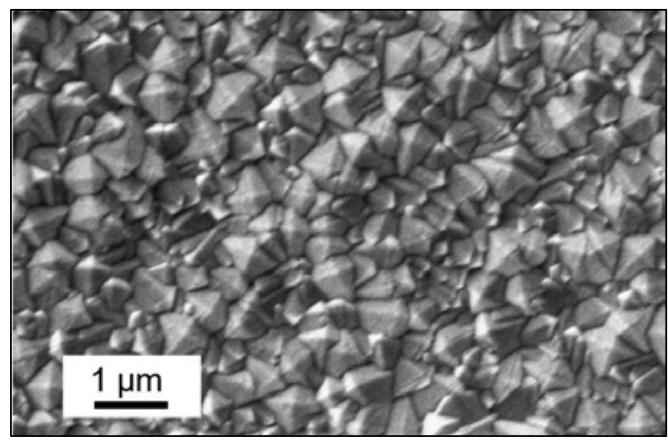

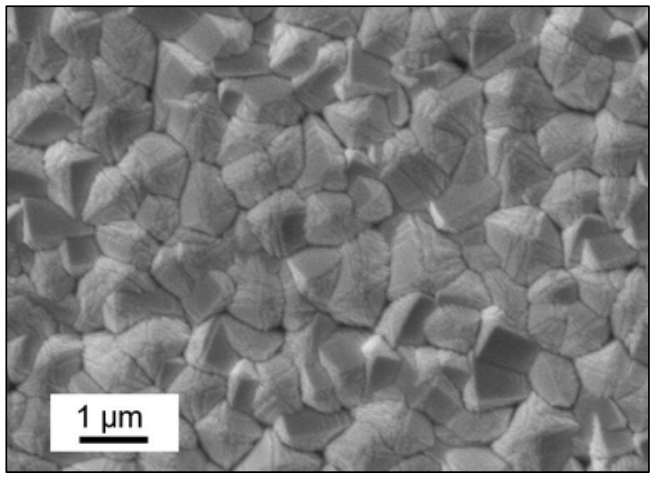

Figure 9. Cross-sectional and surface morphology for TiN layers with (a) golden (b) brown (c) brown color on sapphire. The figure also indicates preferred crystallographic orientation, growth rate and $\mathrm{N} / \mathrm{Ti}$ ratio.

\section{Conclusions}

A simplified kinetic model associated with heat and mass transport for TiN film growth was proposed. $\mathrm{TiCl}_{3}$ and $\mathrm{TiCl}_{4}$ are the most important $\mathrm{Ti}$-containing gas-phase species. These species are adsorbed on the growing surface with an activation energy close to $43 \mathrm{~kJ} / \mathrm{mol}$. The model has been validated within a broad range of process parameters (temperature, N/Tigas-phase ratio, pressure).

The relationship between growth rate, supersaturation, deposition temperature and preferred orientation was studied. It was shown that the orientation of TiN films on non-orientated substrates is influenced by both supersaturation and deposition temperature. TiN films with (111) dominated orientation are preferably grown at low supersaturation and high temperature while (200) and (220) preferred orientation at high supersaturation and low temperature. On (0001) sapphire single crystal, TiN thin films with (111) preferred orientation are most likely to be growing. There is no obvious relationship between the golden color and texture.

Golden TiN films were obtained when the growth rate is lower than $0.4 \mu \mathrm{m} / \mathrm{h}$. Otherwise, TiN films are brown because of columnar structure. On (0001) sapphire single crystals, TiN films should be thick $(\approx 3 \mu \mathrm{m})$ and dense enough to obtain a golden color. The main characteristic of golden TiN films is found to be a dense structure, whatever the process parameters used to get this property.

Supplementary Materials: Table S1: Governing equations of multicomponent mass and heat transfer. Table S2: The gas phase reactions and rate constant for reaction $\mathrm{K}$ is represented in the standard Arrhenius form. Table

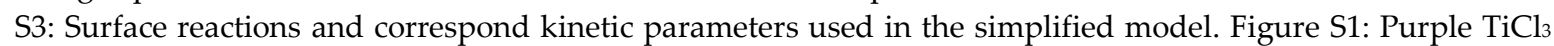
films on the quartz tube. Figure S2: The surface morphology of polycrystalline TiN with golden color on WCCo.

Author Contributions: Conceptualization, Michel Pons, Frederic Mercier and Raphaël Boichot; Experiments, Juan Su; Simulation, Juan Su, Michel Pons, Elisabeth Blanquet and Raphaël Boichot. Writing-Original Draft Preparation, Juan Su.; Writing-Review \& Editing, Michel Pons, Frederic Mercier, Elisabeth Blanquet and Raphaël Boichot; Project Administration, Raphaël Boichot. 
Funding: This research was supported by Carnot Institute 'Énergies du Futur' for the project "AlN pour materiaux refractaires fonctionnels' and by the Centre of Excellence of Multifunctional Architectured Materials "CEMAM" [grant number ANR-10-LABX-44-01].

Acknowledgments: The authors want to thank R. Reboud for emergency management during experiments, M. Jaquemin for help in experiments, S. Coindeau and T. Encinas for discussions on the XRD results.

\section{References}

1. Echigoya, J.; Liu, Z.-t.; Imamura, A.; Takatsu, S. Transmission electron microscopy studies of growth and interface structure of chemically vapour deposited TiC and TiN films on WC-Co alloy substrates. Thin Solid Films 1991, 198, 293-300, doi:10.1016/0040-6090(91)90347-Z.

2. Prengel, H.G.; Pfouts, W.R.; Santhanam, A.T. State of the art in hard coatings for carbide cutting tools. Surface and Coatings Technology 1998, 102, 183-190, doi:10.1016/S0257-8972(96)03061-7.

3. Matei, A.A.; Pencea, I.; Branzei, M.; Tranca, D.E.; Tepes, G.; Sfatb, C.E.; Ciovica, E.; Gherghilescu, A.I.; Stanciu, G.A. Corrosion resistance appraisal of TiN, TiCN and TiAlN coatings deposited by CAE-PVD method on WC-Co cutting tools exposed to artificial sea water. Applied Surface Science 2015, 358, 572-578, doi:10.1016/j.apsusc.2015.08.041.

4. Rebenne, H.E.; Bhat, D.G. Review of CVD TiN coatings for wear-resistant applications: deposition processes, properties and performance. Surface and Coating Technology 1994, 63, 1-13, doi:10.1016/S02578972(05)80002-7.

5. Wagner, J.; Mitterer, C.; Penoy, M.; Michotte, C.; Wallgram, W.; Kathrein, M. The effect of deposition temperature on microstructure and properties of thermal CVD TiN coatings. International Journal of Refractory Metals and Hard Materials 2008, 26, 120-126, doi:10.1016/j.ijrmhm.2007.01.010.

6. Kashani, H.; Sohi, M.H.; Kaypour, H. Microstructural and physical properties of titanium nitride coatings produced by CVD process. Materials Science and Engineering A 2000, 286, 324-330, doi:10.1016/S09215093(00)00744-9.

7. Fiordalice, R.W.; Hegde, R.I.; Kawasaki, H. Orientation control of chemical papor deposition TiN film for barrier applications. Journal of the Electrochemical Society 1996, 143, doi:10.1149/1.1836949.

8. DelaCruz, S.; Wang, Z.; Cheng, P.; Carraro, C.; Maboudian, R. TiN diffusion barrier for stable W/SiC(0001) interfaces in inert ambient at high temperature. Thin Solid Films 2019, 670, 54-59, doi:10.1016/j.tsf.2018.11.058.

9. Sato, M.; Takeyama, M.B. Relationship between TiN films with different orientations and their barrier properties. Japanese Journal of Applied Physics 2018, 57, 07MB01-07MB03, doi:10.7567/JJAP.57.07MB01.

10. Grosso, S.; Latu-Romain, L.; Berthome, G.; Renou, G.; Coz, T.L.; Mantel, M. Titanium and titanium nitride thin films grown by dc reactive magnetron sputtering Physical Vapor Deposition in a continuous mode on stainless steel wires: Chemical, morphological and structural investigations. Surface and Coatings Technology 2017, 324, 318-327, doi:10.1016/j.surfcoat.2017.05.089.

11. Roquiny, P.; Bodart., F.; Terwagne, G. Colour control of titanium nitride coatings produced by reactive magnetron sputtering at temperature less than $100^{\circ} \mathrm{C}$. Surface and Coatings Technology 1999, 116-119, 278283, doi:10.1016/s0257-8972(99)00076-6.

2. Kafizas, A.; Carmalt, C.J.; Parkin, I.P. CVD and precursor chemistry of transition metal nitrides. Coordination Chemistry Reviews 2013, 257, 2073-2119, doi:10.1016/j.ccr.2012.12.004.

13. Choy, K.L. Chemical vapour deposition of coatings. Progress in Materials Science 2003, 48, 57-170, doi:10.1016/S0079-6425(01)00009-3. 
320 14. García, J.; Pinto, H.; Ramos-Moore, E.; Espinoza, C.; Östby, J.; Coelho, R. In-situ high temperature stress analysis of $\operatorname{Ti}(\mathrm{C}, \mathrm{N})$ coating on functionally graded cemented carbides by energy dispersive synchrotron X-ray diffraction. International Journal of Refractory Metals and Hard Materials 2016, 56, 27-34, doi:10.1016/j.ijrmhm.2015.12.001.

15. Tang, S.; Gao, S.; Wang, S.; Wang, J.; Zhu, Q.; Chen, Y.; Li, X. Characterization of CVD TiN coating at different deposition temperatures and its application in hydrocarbon pyrolysis. Surface and Coatings Technology 2014, 258, 1060-1067, doi:10.1016/j.surfcoat.2014.07.029. von Fieandt, L.; Larsson, T.; Lindahl, E.; Bäcke, O.; Boman, M. Chemical vapor deposition of TiN on transition metal substrates. Surface and Coatings Technology 2018, 334, 373-383, doi:10.1016/j.surfcoat.2017.11.063.

18. Spee, C.I.M.A.; Driessen, J.P.A.M.; Kuypers, A.D. Low temperature deposition of TiN ceramic material by

19. Kuo, D.-H.; Huang, K.-W. Kinetics and microstructure of TiN coatings by CVD. Surface and Coatings Technology 2001, 135, 150-157, doi:10.1016/S0257-8972(00)00986-5.

Jiang, C.; Goto, T.; Hirai, T. Morphology and preferred orientation of titanium nitride plates prepared by chemical vapour deposition. Journal of Materials Science 1994, 29, 669-675, doi:10.1007/BF00445977. Nakanishi, N.; Mori, S.; Kato, E. Kinetics of chemical vapor deposition of titanium nitride. Journal of The Electrochemical Society 1990, 137, 322-328, doi:10.1149/1.2086412. Larson, R.S.; Allendorf, M.D. A reaction mechanism for titanium nitride $\mathrm{CVD}$ from $\mathrm{TiCl}_{4}$ and $\mathrm{NH}_{3}$; SAND968443·UC-401, Sandia National Laboratories: California, May 5-10, 1996, 1996; pp 41-46. Allendorf, M.D.; Arsenlis, A.; Bastasz, R.; Colvin, M.E.; Evans, G.; Germann, G.; Janssen, C.L.; Larson, R.S.; Melius, C.F.; Osterheld, T.H., et al. Development of a Process Simulation Capability for the Formation of Titanium Nitride Diffusion barriers; SAND97-8235·UC-404, Sandia National Laboratories: California, 1997; pp 1-40. Grujicic, M.; Lai, S.G. Multi-length scale modeling of chemical vapor deposition of titanium nitride coatings. Journal of Materials Science 2001, 36, 2937-2953, doi:10.1023/A:1017958621586. Teyssandier, F.; Allendorf, M.D. Thermodynamics and kinetics of gas-phase reactions in the Ti-Cl-H system. Journal of the Electrochemical Society 1998, 145, 2167-2177, doi:10.1149/1.1838613. J.Herzler; Roth, P. High-temperature decomposition of $\mathrm{TiCl}_{4}$ based on Cl-Concentration measurements. Proceedings of the Combustion Institute 2002, 29, 1353-1359, doi:10.1016/S1540-7489(02)80166-3. Umanskii, S.Y.; Novoselov, K.P.; Minushev, A.K.; Siodmiak, M.; Frenking, G.; Korkin, A.A. Thermodynamics and kinetics of initial gas phase reactions in chemical vapor deposition of titanium nitride. Theroretical study of TiCl4 Ammonolysis. Journal of Computational Chemistry 2001, 22, 1366, doi:10.1002/jcc.1095. Boichot, R.; Coudurier, N.; Mercier, F.; Claudel, A.; Baccar, N.; Milet, A.; Blanquet, E.; Pons, M. CFD modeling of the high-temperature HVPE growth of aluminum nitride layers on c-plane sapphire: from theoretical chemistry to process evaluation. Theoretical Chemistry Accounts 2014, 133, doi:10.1007/s00214-013-1419-8. Bird, R.B.; Stewart, W.E.; lightfoot, E.N. Transport phenomena, Rivesed 2nd ed.; Wiley, J., New York, 2002.

Svehla, R.A. NASA technical report R-132. ; 1962. Institute of Physics for the National Institute of Standards and Technology: Washington, D.C., 1998. 
363 32. Mercier, F.; Shimoda, H.; Lay, S.; Pons, M.; Blanquet, E. Reactive chemical vapor deposition of heteroepitaxial Ti1-xAlxN films. CrystEngComm 2018, 20, 1711-1715, doi:10.1039/c7ce02129a.

33. Kurtz, S.R.; Gordon, R.G. Chemical vapor deposition of titanium nitride at low temperatures. Thin Solid Films 1986, 140, 277-290, doi:10.1016/0040-6090(86)90271-3.

34. Consonni, V.; Rey, G.; Roussel, H.; Bellet, D. Thickness effects on the texture development of fluorine-doped SnO2 thin films: The role of surface and strain energy. Journal of Applied Physics 2012, 111, 033523, doi:10.1063/1.3684543.

$370 \quad 35 . \quad$ Pangarov, N.A. On the crystal orientation of electrodeposited metals. Electrochimica Acta 1964, 9, 721-726, doi:10.1016/0013-4686(64)80060-8.

$372 \quad$ 36. Anderbouhr, S.; Blanquet, E.; Ghetta, V.; Bernard, C. TiN and $\left(\operatorname{Ti}_{1-\mathrm{x}} \mathrm{Al}_{\mathrm{x}}\right) \mathrm{N}$ films obtained by a low pressure chemical vapor deposition process. In Proceedings of Proc 14th Int conf chem vap dep and EUROCVD XI, Pennington, 1997; pp. 356-363.

37. Nah, J.-W.; Kim, B.-J.; Lee, D.-K.; Lee, J.-J. Color, structure, and properties of TiN coatings prepared by plasma enhanced chemical vapor deposition. Journal of Vacuum Science \& Technology A 1999, 17, 463-469, doi:10.1116/1.581607. 


\title{
Supplementary materials
}

\section{Chemical vapor deposition of titanium nitride thin films: kinetics and experiments}

\author{
Juan Su ${ }^{1}$, Raphaël Boichot ${ }^{1,}$, Elisabeth Blanquet ${ }^{1}$, Frédéric Mercier ${ }^{1}$, and Michel Pons ${ }^{1}$
}

\section{Heat and Mass transport model}

The governing equations describing flow dynamics, heat and mass transfer are shown in Table S1. Precursors are very diluted in $\mathrm{H}_{2}$ (more than $90 \%$ in mole fraction of the gaseous phase), so values of the transport properties can be calculated by the kinetic theory of dilute gas[1].

The boundary conditions for heat transfer are: $T=T_{m}$ on the surface of substrate and $T=T_{c}$ on the cooling wall ( $T_{m}$ is measured from IR pyrometer and $T_{c}$ is controlled by a heating and cooling system); the temperature for initial gas-phase species are room temperature. The boundary conditions for mass transfer are: the velocity on the wall is 0 ; the velocity at the inlet is varied to satisfy the calculated flow rates matching the experimental conditions. Outlet condition is zero pressure (compared to the reference working pressure).

Table S1. Governing equations of multicomponent mass and heat transfer (notations are at the end of the document).

\begin{tabular}{|l|l|}
\hline Continuity & $\nabla \cdot \rho \vec{v}=0$ \\
\hline Momentum balance (1) & $\nabla \cdot(\rho \vec{v} \vec{v})=\nabla \cdot \underline{\underline{\tau}}-P+\rho \vec{g}$ \\
& $\underline{\underline{\tau}}=\mu\left(\nabla \vec{v}+(\nabla \vec{v})^{t}\right)-\frac{2}{3} \mu(\nabla \cdot \vec{v}) \cdot \underline{\underline{I}}$ \\
\hline Energy balance (2) & $c_{p} \nabla \cdot(\rho \vec{v} T)=\nabla \cdot(\lambda \nabla T)+\nabla \cdot\left(R T \sum_{i=1}^{N} \frac{D_{i}^{T}}{M_{i}} \frac{\nabla x_{i}}{x_{i}}\right)$ \\
& $+\sum_{i=1}^{N} \frac{H_{i}}{M_{i}} \nabla \cdot \vec{J}_{i}-\sum_{i=1}^{N} \sum_{k=1}^{K} H_{i} v_{i k}\left(\mathcal{R}_{k}^{g}-\mathscr{R}_{-k}^{g}\right)$ \\
\hline Species transport (3) & $\nabla \cdot\left(\rho \vec{v} \omega_{i}\right)=-\nabla \cdot \vec{J}_{i}+M_{i} \sum_{k=1}^{K} v_{i k}\left(\mathcal{R}_{k}^{g}-\mathcal{R}_{-k}^{g}\right) i=1, N$ \\
& $\vec{J}_{i}^{c}=-\sum_{j=1}^{N}\left(\rho D_{i j}\right) x_{j} i=1, N$ \\
& $\vec{J}_{i}^{T}=-D_{i}^{T} \frac{\nabla T}{T} i=1, N$ \\
\hline Ideal gas law (4) & $\rho=\frac{P M}{R T}$ \\
\hline Deposition rate (5) & $R_{s}=\vec{J}_{i} \cdot \vec{n}=\vec{J}_{i}^{c} \cdot \vec{n}+\vec{J}_{i}^{T} \cdot \vec{n} i=1, N$ \\
\hline
\end{tabular}

\section{Gas-phase kinetics pathways}

From thermodynamic equilibrium calculation in chlorination tube, both $\mathrm{TiCl}_{4}$ and $\mathrm{TiCl}_{3}$ should be considered for the gas-phase reactions. The gas-phase kinetic model involves unimolecular 
dissociation reactions (K1-K3) and bimolecular reactions (K4-K17) is summarized in Ref[1] (Table S2). The rate constant for reaction $\mathrm{k}_{\mathrm{k}}$ in this work is represented in the standard Arrhenius form:

$$
k_{k}=\alpha_{k} T^{\beta_{k}} \exp \left(-\frac{E_{\alpha k}}{R T}\right)
$$

Table S2. The rate constant for reaction $\mathrm{K}$ is represented in the standard Arrhenius form: $k_{k}=$ $\alpha_{k} T^{\beta_{k}} \exp \left(-\frac{E_{\alpha k}}{R T}\right)$. For unimolecular reactions, the units of $\alpha_{k}$ are $\mathrm{s}^{-1}$; for bimolecular reactions, the units are $\mathrm{cm}^{3} \mathrm{~mol}^{-1} \mathrm{~s}^{-1}$. All energies are in $\mathrm{kJ} \mathrm{mol}^{-1}$.

\begin{tabular}{|c|c|c|c|}
\hline Reaction $\mathrm{K}$ & $\alpha_{k}$ & $\beta_{k}$ & $E_{\alpha k}$ \\
\hline $\mathrm{K} 1: \mathrm{TiCl}_{4}<->\mathrm{TiCl}_{3}+\mathrm{Cl}$ & $2.32 \mathrm{E}+20$ & -1.17 & 387.9 \\
\hline $\mathrm{K} 2: \mathrm{TiCl}_{3}<->\mathrm{TiCl}_{2}+\mathrm{Cl}$ & $1.02 \mathrm{E}+18$ & -0.742 & 422.6 \\
\hline $\mathrm{K} 3: \mathrm{TiCl}_{2}<->\mathrm{TiCl}+\mathrm{Cl}$ & $3.65 \mathrm{E}+20$ & -1.06 & 509.6 \\
\hline $\mathrm{K} 4: \mathrm{TiCl}_{4}+\mathrm{H}<->\mathrm{TiCl}_{3}+\mathrm{HCl}$ & $5.11 \mathrm{E}+06$ & 2.5 & 12.6 \\
\hline $\mathrm{K} 5: \mathrm{TiCl}_{3}+\mathrm{H}<->\mathrm{TiCl}_{2}+\mathrm{HCl}$ & $1.11 \mathrm{E}+06$ & 2.5 & 33.5 \\
\hline $\mathrm{K} 6: \mathrm{TiCl}_{2}+\mathrm{H}<->\mathrm{TiCl}+\mathrm{HCl}$ & $3.05 \mathrm{E}+06$ & 2.5 & 145.2 \\
\hline $\mathrm{K} 7: \mathrm{TiCl}+\mathrm{H}<->\mathrm{Ti}+\mathrm{HCl}$ & $4.09 \mathrm{E}+05$ & 2.5 & 24.7 \\
\hline $\mathrm{K} 8: \mathrm{H}+\mathrm{Cl}+\mathrm{M}->\mathrm{HCl}+\mathrm{M}$ & $7.20 \mathrm{E}+21$ & -2.0 & 0.0 \\
\hline $\mathrm{K} 9: \mathrm{HCl}+\mathrm{M}->\mathrm{HCl}+\mathrm{M}$ & $7.90 \mathrm{E}+25$ & -3.0 & 445.6 \\
\hline $\mathrm{K} 10: \mathrm{Cl}+\mathrm{Cl}+\mathrm{M}<->\mathrm{Cl}_{2}+\mathrm{M}$ & $2.00 \mathrm{E}+14$ & 0.0 & -7.5 \\
\hline $\mathrm{K} 11: \mathrm{H}+\mathrm{HCl}->\mathrm{Cl}+\mathrm{H}_{2}$ & $1.69 \mathrm{E}+13$ & 0.0 & 17.2 \\
\hline $\mathrm{K} 12: \mathrm{Cl}+\mathrm{H}_{2}->\mathrm{H}+\mathrm{HCl}$ & $2.95 \mathrm{E}+13$ & 0.0 & 21.3 \\
\hline $\mathrm{K} 13: \mathrm{Cl}_{2}+\mathrm{H}<->\mathrm{Cl}+\mathrm{HCl}$ & $8.60 \mathrm{E}+13$ & 0.0 & 5.0 \\
\hline $\mathrm{K} 14: \mathrm{H}+\mathrm{H}+\mathrm{H}_{2}->\mathrm{H}_{2}+\mathrm{H}_{2}$ & $9.70 \mathrm{E}+16$ & -0.6 & 0.0 \\
\hline $\mathrm{K} 15: \mathrm{H}_{2}+\mathrm{H}_{2}->\mathrm{H}+\mathrm{H}+\mathrm{M}$ & $8.80 \mathrm{E}+14$ & 0.0 & 402.1 \\
\hline K16: $\mathrm{H}_{2}+\mathrm{M} \rightarrow \mathrm{H}+\mathrm{H}+\mathrm{M}$ & $2.20 \mathrm{E}+14$ & 0.0 & 402.1 \\
\hline $\mathrm{K} 17: \mathrm{H}+\mathrm{H}+\mathrm{M}->\mathrm{H}_{2}+\mathrm{M}$ & $6.53 \mathrm{E}+17$ & -1.0 & 0.0 \\
\hline
\end{tabular}




\section{Surface kinetics pathways}

The surface reaction rate for adsorbed species $C_{-} s$ which absorb the gas-phase molecules $\mathrm{A}$ is expressed as [2]:

$$
V_{k}=k_{k}[A] \times[C(S)]
$$

The rate constant for reaction $k$ in this work is represented in the standard Arrhenius form:

$$
k_{k}=\alpha_{k} T^{\beta_{k}} \exp \left(-\frac{E_{\alpha k}}{R T}\right)
$$

In which,

$$
\begin{aligned}
& \alpha_{k}=\sqrt{\frac{R}{2 \pi M_{A}}} \frac{1}{\left[\Gamma_{\text {tot }}\right]} \\
& \beta_{k}=0.5
\end{aligned}
$$

The local gas supersaturation near the growing surface has been defined as the sum of the reactants pressure divided by the sum of the species at equilibrium pressure [3]:

$$
\beta=\frac{P_{\mathrm{TiCl}_{3}}+P_{\mathrm{TiCl}_{4}}+P_{\mathrm{NH}_{3}}}{P_{\mathrm{Ti}}^{*}+2 P_{\mathrm{N}_{2}}^{*}}
$$

where $P$ and $P^{*}$ are calculated pressure of species $\left(\mathrm{TiCl}_{3}, \mathrm{TiCl}_{4}\right.$, and $\left.\mathrm{NH}_{3}\right)$ contributing to TiN growth near the growing surface and the equilibrium vapor pressure of gases in a closed volume at the same temperature calculated with Factsage 7.1.

Table S3. Surface reactions and correspond kinetic parameters used in the simplified model. _s is a surface site and $(B)$ is the bulk phase. The surface density is $1.8 \times 10^{-9} \mathrm{~mol} \mathrm{~cm}^{-2}$.

\begin{tabular}{cccc}
\hline Heterogeneous reaction unit CGS (cm-g-s) & \multicolumn{3}{c}{} \\
\hline Surface reactions & $\begin{array}{c}\boldsymbol{\alpha}_{\boldsymbol{k}} \\
\text { Pre exp. factor }\end{array}$ & $\begin{array}{c}\boldsymbol{\beta}_{\boldsymbol{k}} \\
\text { Temp. exp. }\end{array}$ & $\begin{array}{c}\boldsymbol{E}_{\boldsymbol{\alpha} \boldsymbol{k}} / \boldsymbol{R} \\
\text { Activ. temp. (K) }\end{array}$ \\
\hline $\mathrm{TiCl}_{3}+\mathrm{NH}_{2-} s \leftrightarrow \mathrm{N}(B)+\mathrm{TiCl}_{2-} s+\mathrm{HCl}$ & $1 \mathrm{E}+14$ & 0.5 & 4900 \\
$\mathrm{TiCl}_{4}+\mathrm{NH}_{2}(S) \rightarrow \mathrm{N}(\mathrm{B})+\mathrm{TiCl}_{3}(S)+\mathrm{HCl}$ & $1 \mathrm{E}+14$ & 0.5 & 4900 \\
& & 0.5 & 4900 \\
$\mathrm{NH}_{3}+\mathrm{TiCl}_{2-} S \rightarrow \mathrm{Ti}(B)+\mathrm{NH}_{2-} S+\mathrm{HCl}+\mathrm{Cl}$ & $2.4 \mathrm{E}+11$ & 0.5 & 4900 \\
$\mathrm{NH}_{3}+\mathrm{TiCl}_{3}(S) \rightarrow \mathrm{Ti}(B)+\mathrm{NH}_{2}(S)+\mathrm{HCl}+\mathrm{Cl}_{2}$ & $2.4 \mathrm{E}+11$ & & \\
\hline
\end{tabular}




\section{Supplementary results}

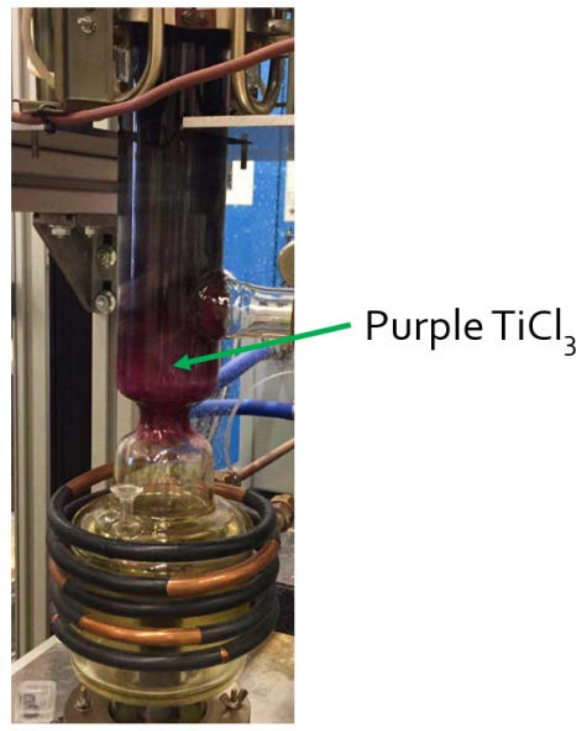

Figure S1. Purple $\mathrm{TiCl}_{3}$ films on the quartz tube.

Figure S1 shows the purple powdered films deposited on the quartz after experiments. In fact, the color of the quartz varied from light purple, dark purple to black with deposition time because the thickness increase.

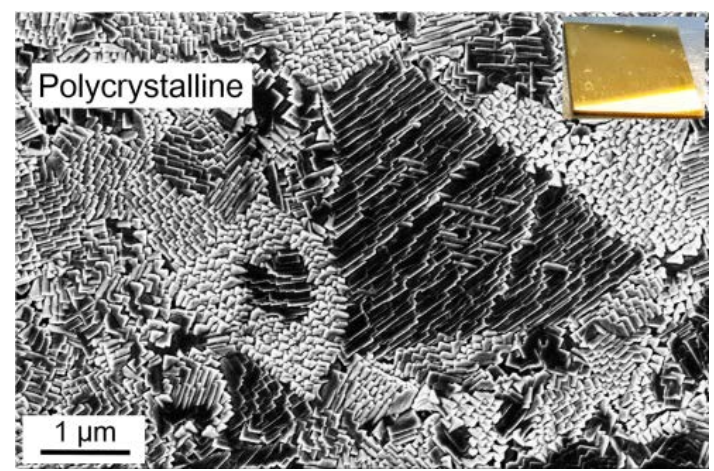

Figure S2. Polycrystalline TiN with golden color on WC-Co obtained from another CVD system in our lab.

\section{References for the supporting information}

1. Teyssandier, F.; Allendorf, M.D. Thermodynamics and kinetics of gas-phase reactions in the Ti-Cl-H system. Journal of the Electrochemical Society 1998, 145, 2167-2177, doi:10.1149/1.1838613.

2. Coltrin, M.E.; Kee, R.J.; Rupley, F.M.; Meeks, E. Surface chemkin; SAND96-8217·UC-405, Sandia National Laboratories: Livermore, California, 1990.

3. Boichot, R.; Coudurier, N.; Mercier, F.; Claudel, A.; Baccar, N.; Milet, A.; Blanquet, E.; Pons, M. CFD modeling of the high-temperature HVPE growth of aluminum nitride layers on c-plane sapphire: from theoretical chemistry to process evaluation. Theoretical Chemistry Accounts 2014, 133, doi:10.1007/s00214-013-1419-8.

\section{Notations and units}

$\begin{array}{lll}R_{\mathrm{S}} & : & \text { surface reaction rate }\left(\mathrm{kg} \cdot \mathrm{m}^{-2} \cdot \mathrm{s}^{-1}\right) \\ \underline{\mathrm{v}} & : & \text { velocity vector }\left(\mathrm{m} \cdot \mathrm{s}^{-1}\right) \\ \mathrm{P} & : & \text { pressure }(\mathrm{Pa}) \\ \mathrm{x}_{\mathrm{i}} & : & \text { species molar fraction of species } \mathrm{i}\end{array}$




\begin{tabular}{|c|c|c|}
\hline$\omega_{i}$ & : & species mass fraction of species $i$ \\
\hline $\mathrm{T}$ & : & temperature $(\mathrm{K})$ \\
\hline g & : & gravity vector $\left(\mathrm{g}=9.81 \mathrm{~m} \cdot \mathrm{s}^{-2}\right)$ \\
\hline $\mathbf{I}$ & : & unity tensor \\
\hline $\mathrm{R}$ & : & universal gas constant (8.314 J.mol-1. $\left.\mathrm{K}^{-1}\right)$ \\
\hline M & : & molar mass of the mixture (kg.mol-1) \\
\hline $\mathrm{N}$ & : & number of gaseous species in the mixture \\
\hline$\rho$ & $:$ & density $\left(\mathrm{kg} \cdot \mathrm{m}^{-3}\right)$ \\
\hline$\lambda$ & : & thermal conductivity of the gas mixture (W. $\left.\mathrm{m}^{-1} \cdot \mathrm{K}^{-1}\right)$ \\
\hline$\mu$ & : & dynamic viscosity of the gas mixture $\left(\mathrm{kg} \cdot \mathrm{m}^{-1} \cdot \mathrm{s}^{-1}\right)$ \\
\hline$C_{p}$ & : & specific heat of the gas mixture $\left(J \cdot \mathrm{kg}^{-1} \cdot \mathrm{K}^{-1}\right)$ \\
\hline$\underline{\mathrm{n}}$ & : & unity vector normal \\
\hline$\rho$ & : & density (kg.m-3) \\
\hline h & : & advection coefficient $\left(\mathrm{W} \cdot \mathrm{m}^{-2} \cdot \mathrm{K}^{-1}\right)$ \\
\hline $\mathrm{T}_{\mathrm{amb}}$ & : & ambient temperature $(\mathrm{K})$ \\
\hline$\sigma_{\text {st }}$ & : & Stefan-Boltzmann constant $\left(\mathrm{W} \cdot \mathrm{m}^{-1} \cdot \mathrm{K}^{-4}\right)$ \\
\hline$\varepsilon$ & $:$ & emissivity \\
\hline $\mathbf{n}$ & : & unity vector normal to the wall \\
\hline $\mathfrak{R}_{g i}$ & : & reaction rate of reaction $\mathrm{i}$ in the gas phase $\left(\mathrm{kg} \cdot \mathrm{m}^{-3} \cdot \mathrm{s}^{-1}\right)$ \\
\hline $\mathbf{J}_{i}^{F}$ & : & diffusive mass flux vector $\left(\mathrm{kg} \cdot \mathrm{m}^{-2} \cdot \mathrm{s}^{-1}\right)$ \\
\hline $\mathbf{J}_{i}^{T}$ & : & thermo-diffusive mass flux vector $\left(\mathrm{kg} \cdot \mathrm{m}^{-2} \cdot \mathrm{s}^{-1}\right)$ \\
\hline$D_{i j}$ & : & multicomponent diffusion coefficients $\left(\mathrm{m}^{-2} \cdot \mathrm{s}^{-1}\right)$ \\
\hline$D_{i}^{T}$ & : & multicomponent thermodiffusion coefficients $\left(\mathrm{kg} \cdot \mathrm{m}^{-1} \cdot \mathrm{s}^{-1}\right)$ \\
\hline$\Gamma_{\text {tot }}$ & : & total surface site concentration $\left(\mathrm{mol} \mathrm{m}^{-2}\right)$ \\
\hline$M_{A}$ & : & Molar mass for gaseous specie $A\left(\mathrm{~kg} \mathrm{~mol}^{-1}\right)$ \\
\hline$E_{\alpha k}$ & : & activation energy for reaction $k\left(\mathrm{~J} \mathrm{~mol}^{-1}\right)$ \\
\hline$V_{k}$ & : & production rate of solid surface for reaction $k\left(\mathrm{~mol} \mathrm{~m}^{-2} \mathrm{~s}^{-1}\right)$ \\
\hline
\end{tabular}

